\title{
Adapting a growth equation to model tree regeneration in mountain forests
}

Received: 25 October 2004/ Accepted: 7 April 2005/Published online: 5 November 2005

(C) Springer-Verlag 2005

\begin{abstract}
Management and risk analysis of protection forests depend on a reliable estimation of regeneration processes and tree growth under different site conditions. While the growth of forest stands and thus the average growth of larger trees is well studied and published in yield tables as well as embodied in numerous simulation models, there is still a lack of information about the crucial initial stages of tree growth. Thus, we evaluated juvenile tree growth for different site conditions in the Swiss Alps and developed an approach to model both the early and later stages of growth based on the Bertalanffy equation. This equation is physiologically well founded and requires only two parameter estimates: a maximum tree height and a growth parameter. Data for the parameter estimation were available from studies of tree regeneration at a range of sites in Switzerland: growth patterns of larch (Larix decidua) were available from a high-elevation afforestation experiment. For spruce (Picea abies), data were obtained from a blowdown area in the Alps. The growth equation was fitted to the observed data and we found a good correlation of the fitted curves with the observed data. The parameter estimates were validated with independent data sets. The extrapolated growth curves, calculated with the estimated growth rates, correspond well to the validation data. Thus, it is possible to use the Bertalanffy
\end{abstract}

Communicated by Hans Pretzsch

A. Rammig $(\bowtie) \cdot$ P. Bebi

WSL, Swiss Federal Institute for Snow and Avalanche Research, Flüelastr.11, 7260 Davos, Switzerland

E-mail: rammig@slf.ch

Tel.: +41-81-4170271

Fax: $+41-81-4170110$

H. Bugmann · L. Fahse

Forest Ecology, Department of Environmental Science, Swiss Federal Institute of Technology, Rämistr. 101, 8092 Zurich, Switzerland equation to model both the early and later stages of growth. With this approach, we provide a basis for modelling the growth of juvenile and mature trees of different tree species in mountain forests of the European Alps.

Keywords Bertalanffy growth equation - Larix decidua $\cdot$ Picea abies $\cdot$ Mountain forest

\section{Introduction}

The understanding of growth processes is important for managing mountain forests. Especially in forests that provide protection function against natural hazards, management and risk analysis often depend on a reliable estimation of regeneration processes and tree growth under different site conditions. Disturbances in such forests may lead to a loss of the protection function, and estimating the duration of regeneration processes after disturbances is crucial for taking management decisions (Schönenberger 2002a, b). Yield tables are available for most commercially important tree species, such as Norway spruce and Larch (Flury 1907; Badoux 1966-1969), and they can be used to predict the average tree growth over a limited spectrum of site conditions. Recently, forest management simulators (e.g. Ek and Monserud 1979; Liu and Ashton 1998; Sterba et al. 2002) and various other models of forest growth (e.g. gap models: Botkin et al. 1972; Pacala et al. 1993; Bugmann 1996; e.g. size class models: Enright and Ogden 1979; Bossel and Krieger 1991) have gained increasing interest. These models use various methods to simulate tree growth (c.f. Hasenauer et al. 2000; Price et al. 2001). However, most of these models consider initial tree heights of more than $1 \mathrm{~m}$, and microsite-dependent regeneration processes are modelled in a simplistic manner, or are ignored entirely. Various investigations, however, have demonstrated that the regeneration process depends on factors such as competition by the tall herb layer, 
browsing and microsite conditions (Peterson and Pickett 1990; Brang 1998; Senn and Schönenberger 2001; Senn and Odermatt 2002; Dovciak et al. 2003; Kupferschmid 2003). Particularly for stand dynamics in mountain forests, the initial stages are crucial, and micro-environmental differences are strong (Schönenberger 2001). Thus, the importance of understanding the initial stages of the life cycle of trees should not be neglected in managing and modelling mountain forests.

The aim of this study was to select, adapt and test a single growth equation that is suitable for modelling the growth of both young and adult trees in mountain forests of the European Alps. Growth processes are well studied, and a large number of growth equations is available (Zeide 1993). As a basis for our evaluation, we used the Bertalanffy equation (Bertalanffy 1957). One advantage of this equation is its simplicity, with only two parameters to estimate. Another advantage is its theoretical derivation from eco-physiological considerations that describe growth as a function of the mass of a body (Pretzsch 2001). Bertalanffy derived the equation from the assumption that the rate of anabolism is proportional to the surface area of an organism, which is equivalent to its mass raised to the power of $2 / 3$, whereas the rate of metabolism is proportional to its volume (Zeide 1993). The equation has often been used to model growth processes of organisms such as fish (e.g. Amaral and Cabral 2004), herbs (Rees et al. 1999), and has also been applied to trees (Zeide 1989, 1993; Kahn 1994).

In this paper, we show how the Bertalanffy equation can be adapted to model the growth of two dominant tree species in the forests of the European Alps, Picea abies and Larix decidua, which are naturally most widespread at elevations above ca. 1,500 m a.s.l (e.g. Brändli 1996; Li et al. 2003). The two species are of crucial importance in forests that protect human infrastructure and settlements against avalanches, rockfall and landslides (Ott et al. 1997). We present the parameterisation and validation of the improved growth equation and show how micro-environmental differences of growth can be detected and modelled.

\section{Material and methods}

\section{Study sites}

For our study, we used height growth data of $P$. abies and $L$. decidua. For parameterisation and validation, sites were chosen that are similar in elevation, aspect and slope. The elevation of the sites ranges from 1,500 to 2,200 $\mathrm{m}$ a.s.l, which corresponds to the subalpine and upper subalpine zone (Ott et al. 1997; Körner 1999). The sites are located on north-, northwest- and northeastfacing slopes (Table 1). Height development of $P$. abies regeneration was measured since 1990 on large blowdown areas at Disentis ("Site D"), located in the upper Rhine valley, and Zweisimmen ("Site Z"), located in the Bernese Alps (Fig. 1). The former P. abies stands on these sites were downed by the storm "Vivian" in 1990 (c.f. Schönenberger 2002a, b; Wohlgemuth and Kull 2002). On $1 \mathrm{~m}^{2}$ plots, growth curves for all spruce trees were obtained by measuring the height of the trees in the years 1992, 1993, 1995, 1998 and 2000. Data of larger trees from managed $P$. abies stands were collected at Hospental ("Site H"), situated close to the Gotthard pass, and were used to investigate the adult stages of tree growth. Height growth at site $\mathrm{H}$ was measured since 1898 in irregular time steps (data from the Growth \& Yield Research Team, Birmensdorf, Switzerland). For the analysis, we used only trees that reached height of more than $26 \mathrm{~m}$ with the age of 116 years. Height growth data of $L$. decidua regeneration were available from a high-elevation afforestation experiment at Stillberg near the upper treeline in the Dischma valley near Davos (Schönenberger and Frey 1988; Schönenberger 2001; Senn and Schönenberger 2001). From the Stillberg data, we selected those from three microsite types: (1) Gullies that are characterised by large amounts of snow in winter and dense vegetation cover in summer, indicating a high moisture and nutrient availability ("Site S1"). On site S1, avalanches and interspecific competition are limiting tree survival and growth. (2) East facing slopes, which are characterised by early disappearance

Table 1 Characteristics of the study sites

\begin{tabular}{|c|c|c|c|c|c|c|}
\hline Site & Abbr. & $\begin{array}{l}\text { Elevation } \\
\text { (m a.s.l) }\end{array}$ & Aspect & Species & Characteristics & Data source \\
\hline Disentis & $\mathrm{D}$ & $1,400-1,550$ & NW & Picea abies & $\begin{array}{l}\text { Natural } \\
\text { regeneration }\end{array}$ & $\begin{array}{l}\text { Wohlgemuth } \\
\text { and Kull (2002) }\end{array}$ \\
\hline Zweisimmen & $\mathrm{Z}$ & $1,475-1,590$ & $\mathrm{~W}, \mathrm{NW}$ & P. abies & $\begin{array}{l}\text { Natural } \\
\text { regeneration }\end{array}$ & $\begin{array}{l}\text { Wohlgemuth } \\
\text { and Kull (2002) }\end{array}$ \\
\hline Hospental & $\mathrm{H}$ & 1,475 & $\mathrm{~N}$ & P. abies & $\begin{array}{l}\text { Thinned } \\
\text { stands }\end{array}$ & $\begin{array}{l}\text { Growth and Yield } \\
\text { Research Team, } \\
\text { Birmensdorf, } \\
\text { Switzerland }\end{array}$ \\
\hline Stillberg & $\begin{array}{l}\text { S1 (gully) } \\
\text { S2 (slope) } \\
\text { S3 (ridge) }\end{array}$ & $2,000-2,230$ & $\mathrm{NO}$ & Larix decidua & $\begin{array}{c}\text { Planted } \\
\text { trees }\end{array}$ & $\begin{array}{l}\text { Schönenberger } \\
\text { and Frey (1988) }\end{array}$ \\
\hline
\end{tabular}


Fig. 1 Map of Switzerland. The study sites are marked: in Zweisimmen $(Z)$, Hospental $(H)$ and Disentis $(D)$ data for Picea abies were collected. At Stillberg $(S)$, Davos, data for Larix decidua were collected

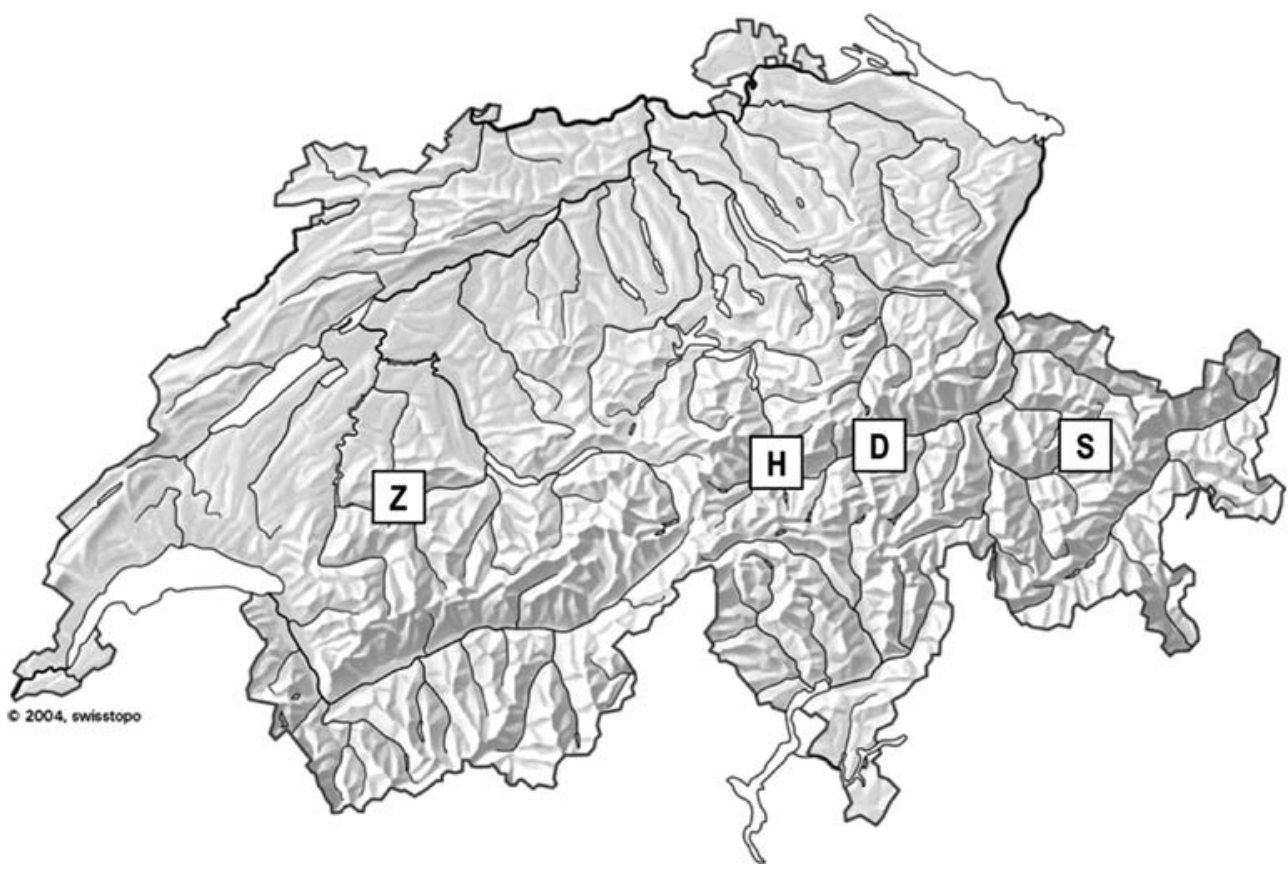

of snow and high insolation ("Site S2"). The microsite type S2 is quite favourable for tree survival and growth in spite of the high insolation. (3) Ridges that are exposed to wind and therefore free of snow in winter ("Site S3"). On the site type S3, trees are mainly endangered by frost drought (Schönenberger 1975; Schönenberger and Frey 1988). Trees were measured repeatedly at different time intervals. Each tree included in the analysis was measured not less than three times. Browsed or damaged trees were excluded from the analysis.

The Bertalanffy growth equation (Bertalanffy 1957)

To predict the height growth of trees with different ages, we used the growth equation of Bertalanffy (1957):

$H(t)=H_{\max } \times\left(1-\mathrm{e}^{-g t}\right)^{3}$,

where $H$ is tree height, $H_{\max }$ is maximum height, $g$ is the growth rate and $t$ the age of the tree. However, it is well known that particularly in mountain forests, height increment depends primarily on tree height rather than on tree age (Ott et al. 1997). Thus, Eq. 1 was transformed so that tree height is calculated from height in the preceding year and not from tree age. The first step was to solve Eq. 1 for $t$ :

$t=\ln \left(1-\left(\frac{H(t)}{H_{\max }}\right)^{1 / 3}\right) /-g$

The second step was to solve $\mathrm{H}(\mathrm{t}+1)$ for $\mathrm{t}$ in an analogous way. Finally we get:

$H(t+1)=H_{\max } \times\left(1-\left(1-\left(\frac{H(t)}{H_{\max }}\right)^{\frac{1}{3}}\right) \times \mathrm{e}^{-g}\right)^{3}$.
The advantage of this transformation is that the height increment of a tree does not depend on its age. Moreover, in Eq. 3, height is calculated in discrete time steps that correspond to the empirical data that were measured once per year.

\section{Parameter estimation}

To estimate the parameter $g$ for Eq. 3, we used data from site D (for P. abies) and S1 (for L. decidua). Initial heights $H\left(t_{0}\right)$, which we define as the height of the tree in the year of germination, were measured on the blowdown area (for P. abies). Germinated larch trees were measured before planting (Schönenberger and Frey 1988). Maximum tree height $H_{\max }$ for $P$. abies was estimated from observations on stands close to the blowdown area (Schönenberger, personal communication). For $L$. decidua, the maximum tree height was estimated from observations and from the literature. While keeping the parameter $H_{\max }$ constant, the parameter $g$ was estimated for each measured growth curve individually with a nonlinear curvefit (package nls, SPLUS 2000) for Eq. 1. The estimated values for $H\left(t_{0}\right)$, $H_{\max }$ and $g$ were used in Eq. 3 to predict the height increment for each individual tree.

\section{Statistical evaluation}

To evaluate the quality of the parameter estimation, the predicted values $\hat{y}_{i}$ were derived by inserting the individually estimated growth parameters $g$ for each measured tree in Eq. 3. As a deviance measure, the root mean square error (RMSE) was calculated 
$\operatorname{RMSE}=\left\{\frac{\sum\left(y_{i}-\hat{y}_{i}\right)^{2}}{n}\right\}^{\frac{1}{2}}$,

where $y_{i}$ represents the observed values, $\hat{y}_{i}$ the predicted values and $n$ the number of pairs. As a measure of the explained proportion of variation, the modelling efficiency (EF) was calculated (Mayer and Butler 1993):

$\mathrm{EF}=1-\frac{\sum\left(y_{i}-\hat{y}_{i}\right)^{2}}{\sum\left(y_{i}-\bar{y}\right)^{2}}$,

where $\bar{y}$ represents the observed mean. A linear regression was fitted to the observed versus predicted values to identify any bias in the intercept and slope. Due to temporal dependency of the data, a simultaneous $F$-test could not be calculated.

To show that the Bertalanffy equation is capable of simulating the variation of the growth curves, an envelope describing the expected range of variability was derived, as follows. First, from all estimated growth parameters $g$ the average growth parameter and its standard deviation were calculated. Second, the standard deviation was added to or subtracted from the average growth parameter, respectively, and the model was initialized with values for initial height $H\left(t_{0}\right)$ and maximum height $H_{\max }$. Below, these envelopes are referred to as the "standard deviation curves". They were compared to the range of observed individual growth curves, and the proportion of observed curves that lay within the standard deviation curves, $C_{i}$, was calculated as

$C_{i}=100-\left(\frac{C_{o}}{N} \times 100\right)$,

where $C_{o}$ is the number of individual observed height growth curves, with at least one point exceeding the estimated standard deviation curves, and $N$ is the number of trees.

Quality of the parameter estimation

The quality of the nonlinear curve fit was evaluated for each tree by comparing the individually fitted curves to the individually observed growth curves (for P. abies on the site D and L. decidua on the site S1), and calculating the RMSE, the EF and a linear regression. Additionally, the proportion of growth curves within the range of the standard deviation was determined $\left(C_{i}\right)$.

\section{Validation}

To estimate the predictive power of the fit, we compared the curve fit of the site D (for P. abies) and S1 (for $L$. decidua) with observed height growth curves from independent measurements on the sites $\mathrm{Z}, \mathrm{H}$ (for $P$. abies) and S2 (for $L$. decidua). The proportion of observed growth curves within the range of the estimated standard deviation curves was determined $\left(C_{i}\right)$.

\section{Results}

Height growth of P. abies

On the blowdown area, initial heights $H\left(t_{0}\right)$ of germinated $P$. abies trees were found to be in the range between 1 and $5 \mathrm{~cm}$. From observations before the blowdown (Schönenberger, personal communication) and measurements on the edge of the blowdown area, $H_{\max }$ was estimated to be $30 \mathrm{~m}$. After Ott et al. (1997) and Schönenberger (personal communication), the maximum height of stands at site conditions similar to those in Disentis varies of $\pm 15 \%$, which only caused changes in the initial slope of $\pm 8 \mathrm{~cm}$ within the first 5 years (detailed results not shown). Thus, $H_{\max }$ was held constant for further analysis. The growth parameter $g$ was estimated for observed growth curves of 15 trees (Fig. 2a) on the site D and ranged between 0.026 and 0.035 year $^{-1}$. The individually predicted and observed height growth curves for the site D were compared (Fig. 2a). In the model, a bias was identified with a slight underprediction of heights between 0 and $20 \mathrm{~cm}$ and an overprediction of heights between 80 and $160 \mathrm{~cm}$ (Fig. 2a). This is confirmed by the results of the linear regression (Table 2), which yielded a slope $=1.3$ and intercept $=2.8$. However, for tree heights between 1 and $160 \mathrm{~cm}$, there is a RMSE of only $17.8 \mathrm{~cm}$ and the modelling efficiency is high (Power 1993), with $70 \%$ of the observed variability being explained by the model (Fig. 2a). From the individual curve fits, a mean $g$ of $0.030 \pm 0.003$ year $^{-1}$ was calculated. Thus, the mean curve (Fig. 3a, dashed line) was calculated using $g=0.030$ year $^{-1}$ and $H\left(t_{0}\right)=1 \mathrm{~cm}$ in Eq. 3. The lower standard deviation curve was calculated using $g=0.027$ year $^{-1}$ and an initial height $H\left(t_{0}\right)=0.01 \mathrm{~cm}$. The value of $0.01 \mathrm{~cm}$ was chosen as an arbitrary value close to zero. The upper standard deviation curve was calculated using $g=0.033$ and an initial height $H\left(t_{0}\right)=5 \mathrm{~cm}$ (Fig. 3a, solid lines). 93\% of the observed growth curves lie within the range of the standard deviation curves (Fig. 3a). Thus, the range of the standard deviation curves represents the envelope of the observed growth curves fairly well.

The curve fit for site $\mathrm{D}$ was validated with data from 37 trees on site $\mathrm{Z}$ (Fig. 4a) by comparing the mean estimated growth curve for site $D$ to observed individual growth curves of site Z. Despite the high variability in the individual observed growth curves, only 7 out of 37 curves exceed the range of the standard deviation curves $\left(C_{i}=81 \%\right.$; Fig. $\left.4 \mathrm{a}\right)$. The curve fit for the site $\mathrm{D}$ was also validated for trees $>7 \mathrm{~m}$ with data from the site $\mathrm{H}$ (Fig. 4b). The $C_{i}=74 \%$ indicates that a high proportion of observed growth curves lie within the range of the standard deviation curves. 

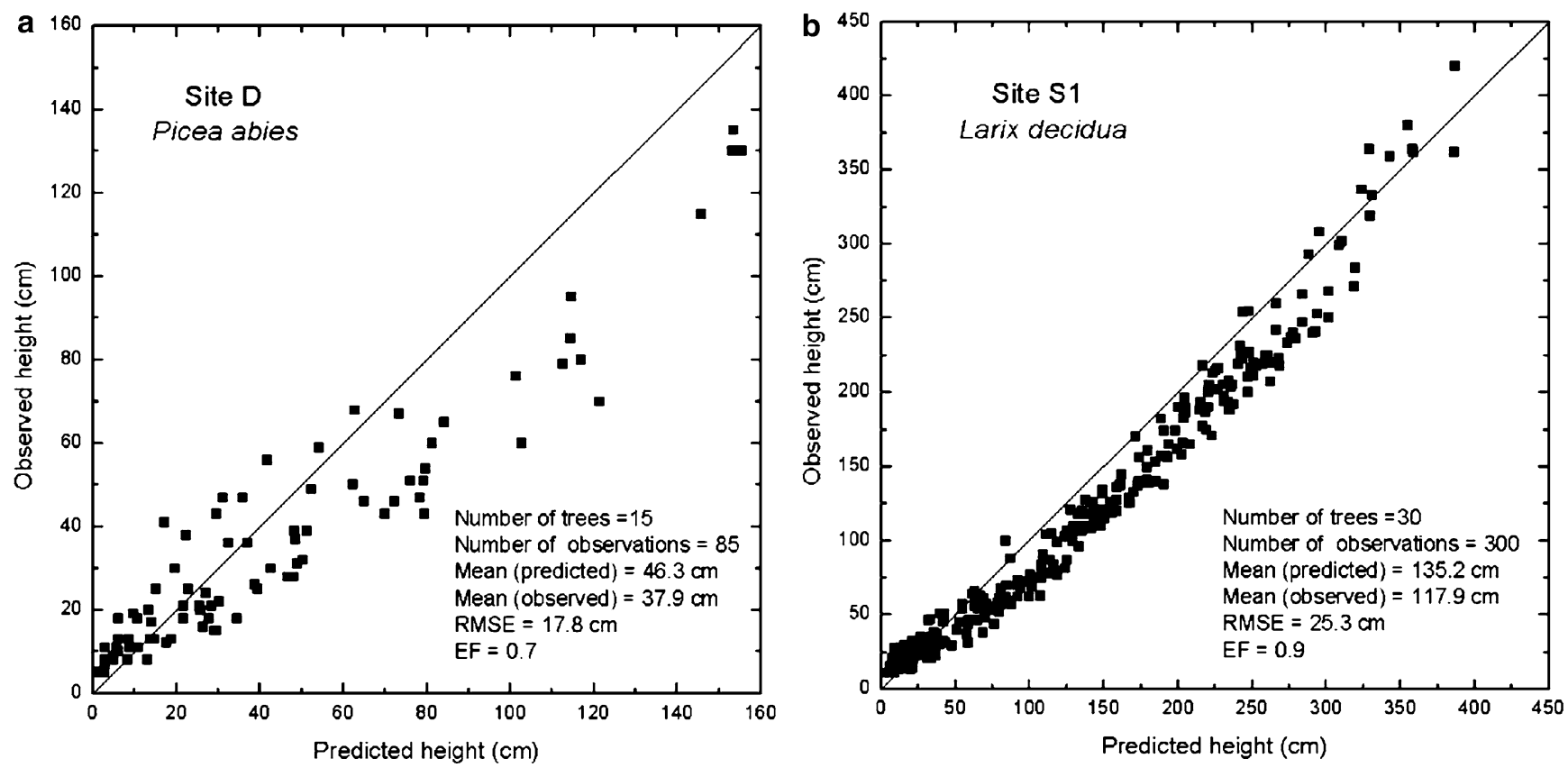

Fig. 2 Quality of the parameter estimation for each growth curve. Comparison of the predicted and the observed values for a the site D and $\mathbf{b}$ the site $\mathrm{S} 1$. The $y=x$ line is marked (black line)

Height growth of L. decidua

As for P. abies, initial heights $H\left(t_{0}\right)$ for $L$. decidua ranged between 1 and $5 \mathrm{~cm}$ (Schönenberger and Frey 1988). From observations and literature, $H_{\max }$ was found to be $8 \mathrm{~m}$ (Essig 2004). The curve fit for $30 \mathrm{~L}$. decidua-trees on site $\mathrm{S} 1$ resulted in the growth parameter $g$ ranging between 0.022 and 0.051 year $^{-1}$. The individually predicted and observed height growth curves were compared (Fig. 2b). Again, the model slightly underpredicts heights between 1 and $20 \mathrm{~cm}$, which results in an slope $=0.9$ and intercept $=-5 \mathrm{~cm}$ in the linear regression. However, the model has a high modelling efficiency as the model explains $90 \%$ of the variability in the data (Fig. 2b). The deviance measure (RMSE $=25.3 \mathrm{~cm}$ ) for trees between $1 \mathrm{~cm}$ and $4 \mathrm{~m}$ is comparatively low. From the individual curve fits, a mean $g$ of $0.037 \pm 0.008$ year $^{-1}$ was calculated. Thus, the mean curve (Fig. 3b, dashed line) was calculated using $g=0.037$ year $^{-1}$ in Eq. 3. The lower standard deviation curve was calculated using $g=0.029$ year $^{-1}$ and an initial height $H\left(t_{0}\right)=0.01 \mathrm{~cm}$, the upper standard deviation curve (Fig. 3b, solid lines) was calculated using $g=0.046$ year $^{-1}$ and an initial height $H\left(t_{0}\right)=5 \mathrm{~cm}$ in Eq. 3 . The individual growth curves for the site S1 show a

Table 2 Results of the linear regression for individual curve fits of the sites D and $\mathrm{S} 1$

\begin{tabular}{llll}
\hline Site & $R^{2}$ & Slope & Intercept \\
\hline $\mathrm{D}$ & 0.90 & 1.3 & -2.8 \\
$\mathrm{~S} 1$ & 0.97 & 0.9 & -5.0 \\
\hline
\end{tabular}

very high variability (Fig. 3b), which results in a high standard deviation. However, still $73 \%$ of the observed individual growth curves lie within the range of the standard deviation curves. Thus, the fitted curves correspond well to the observed growth curves, except a few slow-growing outliers. The curve fit for site S1 was validated with data of 77 trees from site S2 (Fig. 4c). The mean estimated growth curve for site S1 was compared to the individual growth curves of site S2. Mainly slowgrowing trees exceed the range of the standard deviation curves. However, the proportion of curves within the range of the standard deviation curves is high $\left(C_{i}=87 \%\right)$. Additionally, the individually fitted growth parameters $g$ for the sites S1 and S3 were compared (Fig. 5a). At site $\mathrm{S} 3$, trees grow significantly slower $(T=4.95, P<0.001)$. Trees on the site $\mathrm{S} 1$ are significantly taller (Fig. 5b, $T=4.90, P<0.001$ ).

\section{Discussion}

A large body of theoretically derived growth equations are available to investigate ecological problems. For biological applications it is often preferable to use a growth equation that is simple, with only few parameters to estimate, but still describing the process with sufficient accuracy (Zeide 1993). The Bertalanffy equation (Bertalanffy 1957) has frequently been used to model different organisms (fish: Amaral and Cabral 2004; lobsters: Cheng and Kuk 2002; thistles: Rees et al. 1999), and has also been broadly used to describe tree growth (Zeide 1993; Zhang et al. 1996). It is theoretically derived from physiological mechanisms of growth 


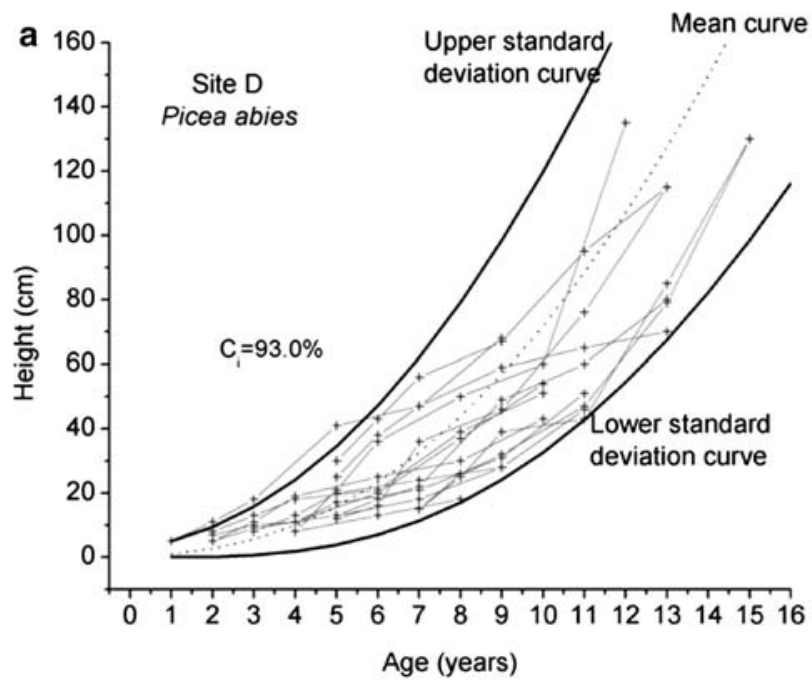

Fig. 3 Observed individual growth curves (grey lines with crosses) and the estimated mean growth curve (dashed black line) for Picea abies (a) and Larix decidua (b). The solid black lines delineate

(Bertalanffy 1957). In this study, we were able to show that it is possible to transform and to parameterise the Bertalanffy equation to model tree growth for both the early and the later stages for tree species in mountain forests of the European Alps under different site conditions. We could also show that it is possible to validate the model's prediction with independent data sets.

The Bertalanffy equation was transformed in such a way that tree height is calculated from the height in the preceding year rather than from the age of the tree. It is well known that increment is a function of size, e.g. tree increment is a function of tree height and environmental variables. Additionally, the initial height can be varied in the transformed Bertalanffy equation. An offset in tree height by $5-10 \mathrm{~cm}$ can be observed in the first growing season (Figs. 3a, 4a). This offset can be modelled with the Bertalanffy equation by varying the initial height $H\left(t_{0}\right)$. Since the investigated trees from site D and S1 are far from approaching maximum tree height, the maximum tree height parameter was estimated from earlier observations on the stand prior to the blowdown (site D) and from observations on comparable sites with mature trees close to the afforestation area Stillberg (site S1, S2, S3). It is clear that large-scale effects such as the changes of growing conditions along extended elevational gradients influence maximum tree height more than micro-scale effects (Ott et al. 1997; Körner 1999). However, a variation of maximum tree height within a range of $\pm 15 \%$ in the Bertalanffy equation does not cause strong changes $( \pm 8 \mathrm{~cm}$ after 5 years) in the initial slope of the growth curve.

In the growth patterns of $P$. abies and L. decidua with heights from $1 \mathrm{~cm}$ to $5 \mathrm{~m}$, a large variability can be observed. This variability can be explained by the extensive small-scale variation in environmental conditions that are typical of mountain ecosystems (Turner 1988). In mountain forests, the initial stages of tree life

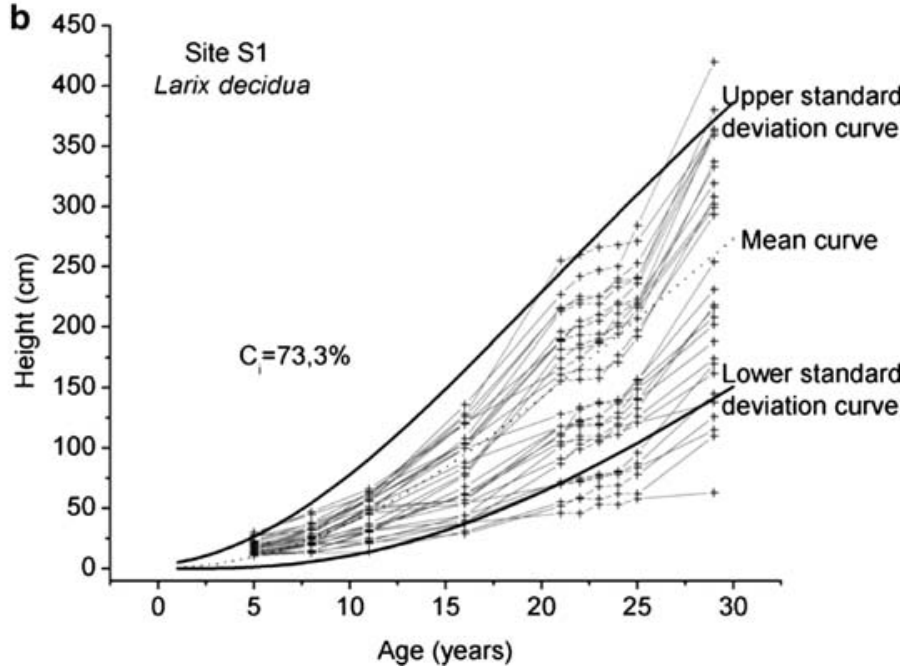

the standard deviation of the estimated growth curve. $C_{i}$ gives the proportion of growth curves within the standard deviation curves

are crucial. Small trees are exposed to various hazards such as snow creep, browsing and snow mould that results from long lasting snow packs (Kräuchi et al. 2000). Moreover, intraspecific competition is high. Tall herbs or thick moss layers reduce or even inhibit the growth and survival of trees (Ponge et al. 1998). This leads to a high variability not only in tree heights but also in the yearly increment of trees with the same age. Detecting differences in growth patterns on different micro-sites is only possible with (1) a high sample size and (2) distinct differences in micro-sites, which is the case for sites $\mathrm{S} 1$ and S3. For L. decidua on sites S1 and S3, a large sample size is available. Microsite-specific variation at site D is included in the range of estimated heights for $P$. abies, which results in a broad range of estimates. It can be assumed that with a larger sample size, it would be possible to detect microsite-specific differences in growth also for site D. When fitting the Bertalanffy growth curve to individually measured growth curves, high EFs $(E F=0.7$ for spruce and 0.9 for larch) can be achieved, even if there is still some bias. As a matter of fact, the bias in the model for $P$. abies may result from a low sample size of trees taller than $1 \mathrm{~m}$. Moreover, for $L$. decidua it could be shown that the model is not biased and fits well. By varying the growth parameter $g$ by its standard deviation, the variability in the empirical growth curves can be reproduced quite well. It is possible to apply the estimated range to sites that are similar in elevation and exposition. Thus, it can be concluded, that our approach is highly suitable for modelling the range of potential growth curves of juvenile trees. It is notable that the Bertalanffy equation as calibrated for the range of growth of small spruce trees $(<160 \mathrm{~cm})$ is also capable of predicting the height of much taller trees $(10-25 \mathrm{~m})$. The $\mathrm{H}$-site is located close to the D-site (Fig. 1) and is similar to the D-site in elevation and aspect (Table 1). The high correlation between the 

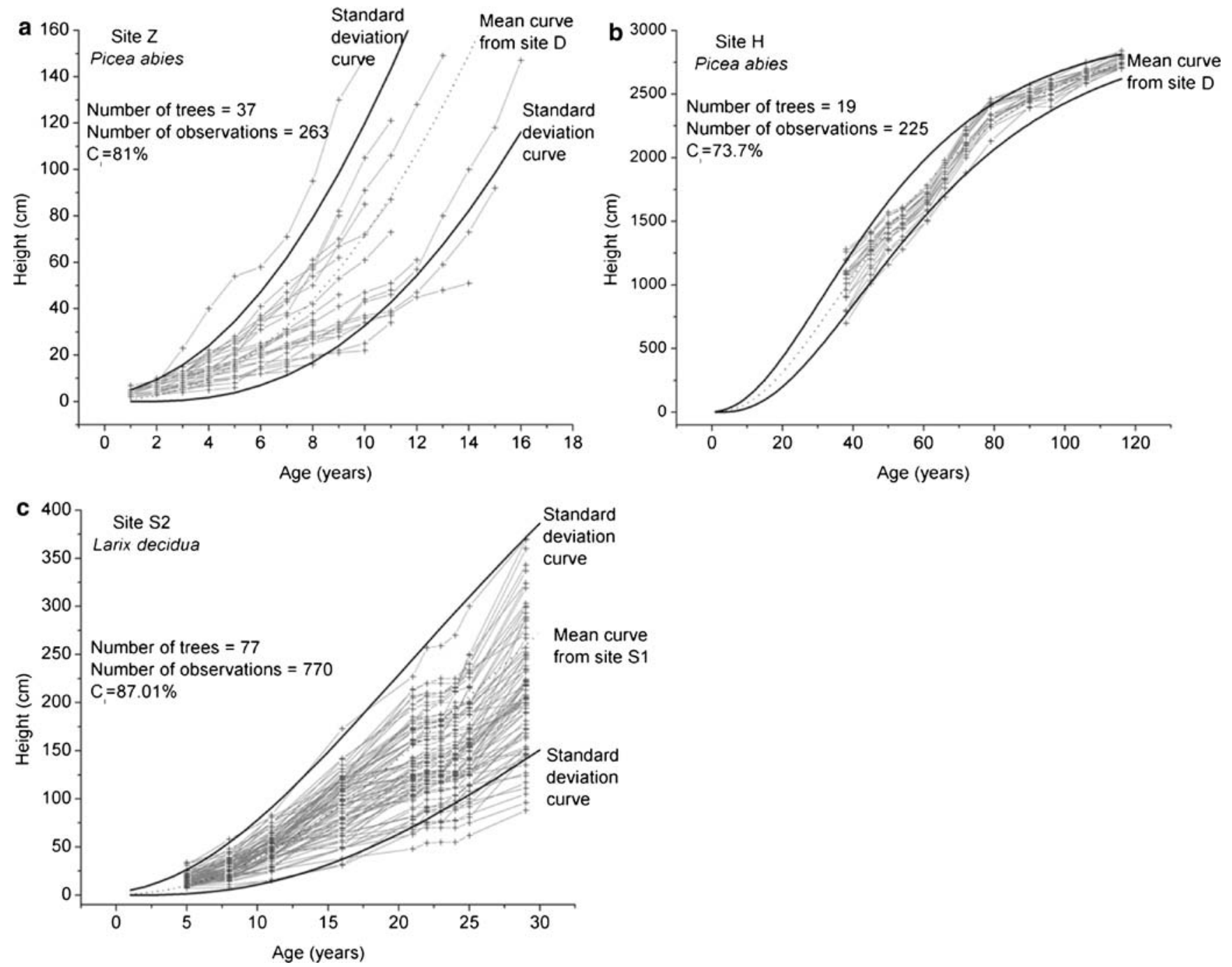

Fig. 4 Validation: a and b Comparison of the individual observed growth curves for Picea abies (grey lines with crosses) with the mean estimated growth curve from site D (dotted black line) and its standard deviation (solid black lines). c Comparison of the individual observed growth curves for Larix decidua (grey lines

with crosses) with the mean estimated growth curves from site $\mathrm{S} 1$ (dotted black line) and its standard deviation (solid black lines). $C_{i}$ gives the proportion of growth curves within the standard deviation curves
Fig. 5 a Comparison of the estimated growth parameters $g$ of the sites $\mathrm{S} 1$ and $\mathrm{S} 3$. The boxes include $50 \%$, the whiskers from 5 to $95 \%$ of the observations. The line in the box denotes the median, the square the mean. Results of the $T$-test are given in the graph. The asterisks indicate that there is a significant difference between the two samples $(P<0.001)$. b Comparison of the mean heights of the sites S1 and S3
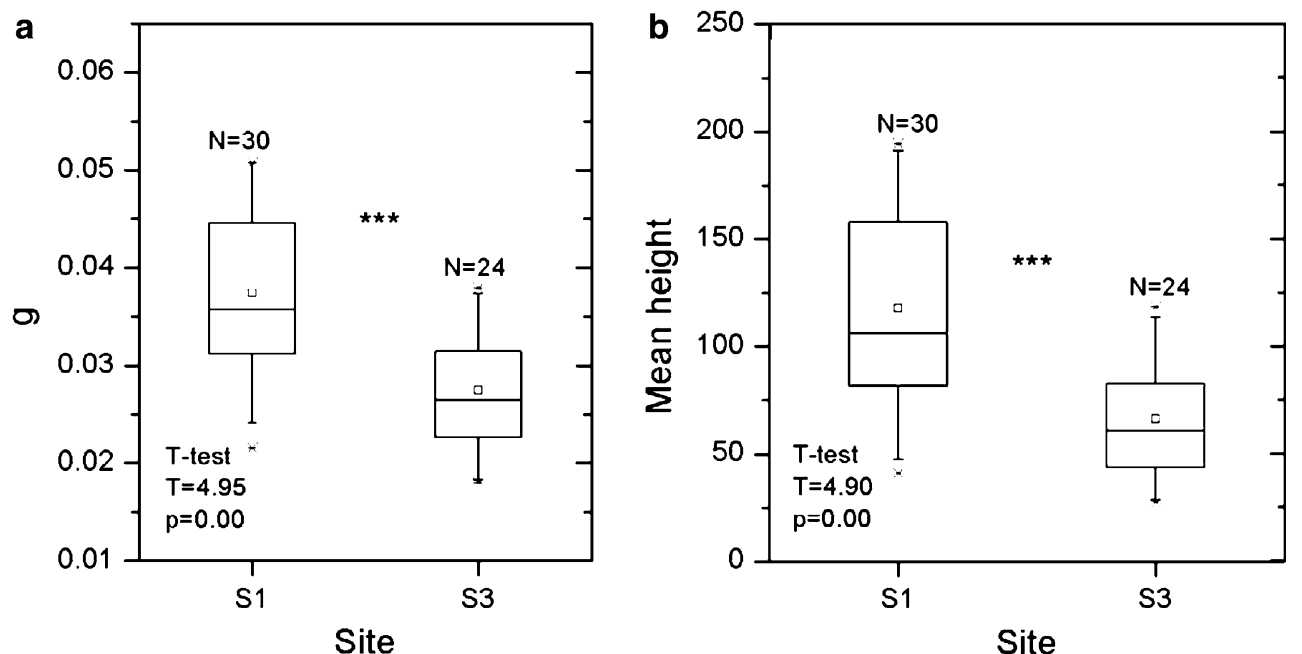
predicted growth range and the observed growth curves shows that the Bertalanffy equation is suitable to predict height growth of larger trees. Kahn (1994) and Zeide (1993) have already demonstrated the good fit of the curve for taller trees. Thus, it can be concluded that the Bertalanffy equation can be used to predict future tree growth from growth coefficients estimated from small trees. This is an important advantage particularly for using this equation in regeneration modules of forest models.

Small-scale environmental variation, which is very strong within the subalpine environment, highly influences the growth of young larches. Li et al. (2003) concluded in their study in the Austrian Alps that microclimate associated with micro-sites controls growth during the early life stages of trees. The gullies on site S1 are characterised by long lasting snow packs and high vegetation cover. The advantage for larch on these sites is that in wintertime, the snow pack protects the trees. In contrast to that, on elevated microsites, such as at site $\mathrm{S} 3$, trees are exposed to strong winds in winter and are therefore often snow-free. At such places, trees may be subject to frost drought (Schönenberger 2001). Comparing the mean height and the individual growth parameters of trees on site S1 and S3, significant differences were found. On sheltered gullies (site S1), trees grow significantly better than on exposed sites (site S3). Thus, it can be concluded that by estimating individual growth parameters with the Bertalanffy equation, microenvironmental differences in tree height growth can be captured.

\section{Conclusion}

There is a large body of models for simulating tree growth (e.g. reviews by Hasenauer et al. 2000; Pretzsch 2001; Kupferschmid 2003). However, the initial stages of growth are often neglected in such models. Some models use empirically derived height classes to predict regeneration (e.g. Stewart et al. 2001; Kupferschmid 2003), whereas others use seedling cohorts that are recruited directly into the stand (Price et al. 2001). In gap models, trees start growing with a height of about 2-3 m (Botkin et al. 1972). Using the established and tested Bertalanffy growth equation allows us to model the initial stages and also to predict the range of future growth. The evaluation of the Bertalanffy equation showed that (1) it fits well for the potential range of juvenile tree height development, (2) it can predict adult stages of growth at comparable sites, and (3) micro-environmental differences can be portrayed as well. Thus we conclude that the equation fulfils the important facts for using it in regeneration modules of forest models.

\section{References}

Amaral V, Cabral HN (2004) Ecology of the whiskered sole in the Sado Estuary, Portugal. J Fish Biol 64(2):460-474
Badoux E (1966-1969) Ertragstafeln für Fichte, Tanne, Buche und Lärche. Birmensdorf, Eidg. Anst. forstl. Versuchswes

Bertalanffy Lv (1957) Quantitative laws in metabolism and growth. Quart Rev Biol 32:217-231

Bossel H, Krieger H (1991) Simulation-model of natural tropical forest dynamics. Ecol Model 59:37-71

Botkin DB, Janak JF, Wallis JR (1972) Some ecological consequences of a computer model of forest growth. J Ecol 60:849-872

Brändli UB (1996) Die häufigsten Waldbäume der Schweiz. Birmensdorf, Ber. Eidgenöss. Forsch.anst. Wald Schnee Landsch. 278

Brang P (1998) Early seedling establishment of Picea abies in small forest gaps in the Swiss Alps. Can J For Res 28:626-639

Bugmann H (1996) A simplified forest model to study species composition along climate gradients. Ecology 77:2055-2074

Cheng YW, Kuk AYC (2002) Determination of the unknown age at first capture of western rock lobsters (Palinurus cygnus) by random effects model. Biometrics 58:459-462

Dovciak M, Reich PB, Frelich LE (2003) Seed rain, safe sites, competing vegetation, and soil resources spatially structure white pine regeneration and recruitment. Can J For Res 33:1892-1904

Ek AR, Monserud RA (1979) Performance and comparison of stand growth models based on individual tree and diameterclass growth. Can J For Res 9:231-244

Enright N, Ogden J (1979) Applications of transition matrix models in forest dynamics: Araucaria in Papua New Guinea and Nothofagus in New Zealand. Aust J Ecol 4:3-23

Essig S (2004) Analyse der Höhenentwicklung von Bäumen der Versuchsaufforstung Stillberg and verschiedenen Kleinstandorten der oberen subalpinen Stufe. Master thesis, Fachhochschule Rottenburg

Flury P (1907) Ertragstafeln für die Fichte und Buche der Schweiz. Zürich

Hasenauer H, Burgmann M, Lexer MJ (2000) Konzepte der Waldökosystemmodellierung. Cbl ges Forstwes 117:137-164

Kahn M (1994) Modellierung der Höhenentwicklung ausgewählter Baumarten in Abhängigkeit vom Standort. Forstliche Forschungsberichte. München 325

Körner C (1999) Alpine plant life. Springer, Berlin Heidelberg New York

Kräuchi N, Brang P, Schönenberger W (2000) Forests of mountainous regions: gaps in knowledge and research needs. For Ecol Manage 132:73-82

Kupferschmid AD (2003) Succession in a protection forest after Picea abies die-back. PhD thesis, No. 15228, ETH Zürich

Li M, Yang J, Kräuchi N (2003) Growth responses of Picea abies and Larix decidua to elevation in subalpine areas of Tyrol, Austria. Can J For Res 34:653-662

Liu J, Ashton PS (1998) FORMOSAIC: an individual-based spatially explicit model for simulating forest dynamics in landscape mosaics. Ecol Model 106:177-200

Mayer DG, Butler DG (1993) Statistical validation. Ecol Model 68:21-32

Ott E, Frehner M, Frey H-U, Lüscher P (1997) Gebirgsnadelwälder. Haupt-Verlag, Bern, Stuttgart, Wien

Pacala SW, Canham CD, Silander JA (1993) Forest models defined by field measurements: I. The design of a northeastern forest simulator. Can J For Res 23:1980-1988

Peterson CJ, Pickett STA (1990) Microsite and elevational influences on early forest regeneration after catastrophic windthrow. J Veg Sci 1:657-662

Ponge J-F, André J, Zackrisson O, Bernier N, Nilsson M-C, Gallet C (1998) The forest regeneration puzzle. Bioscience 48:523-530

Power M (1993) The predictive validation of ecological and environmental models. Ecol Model 68:33-50

Pretzsch H (2001) Modellierung des Waldwachstums. Parey Verlag, Berlin

Price DT, Zimmermann NE, Van der Meer PJ, Lexer M, Leadley P, Jorritsma ITM, Schaber J, Clark DF, Lasch P, McNulty S, Wu J, Smith B (2001) Regeneration in gap models: priority issues for studying forest responses to climate change. Clim Change 51:475-508 
Rees M, Sheppard A, Briese D, Mangel M (1999) Evolution of sizedependent flowering in Onopordum illyricum: a quantitative assessment of the role of stochastic selection pressures. Am Nat 154:628-651

Schönenberger W (1975) Standortseinflüsse auf Versuchsaufforstungen an der subalpinen Waldgrenze. Mitteilg. der Schweizerischen Anst. forstliche Versuchswesen 4

Schönenberger W (2001) Cluster afforestation for creating diverse mountain forest structures-a review. For Ecol Manage 145:121-128

Schönenberger W (2002a) Post windthrow stand regeneration in Swiss mountain forests: the first ten years after the 1990 storm Vivian. For Snow Landsc Res 77:61-80

Schönenberger W (2002b) Windthrow research after the 1990 storm Vivian in Switzerland: objectives, study sites, and projects. For Snow Landsc Res 77:9-16

Schönenberger W, Frey W (1988) Untersuchungen zur Ökologie und Technik der Hochlagenaufforstung. Schweiz Z Forstwesen 139:735-820

Senn J, Odermatt O (2002) Impact of browsing ungulates on plant cover and tree regeneration in windthrow areas. For Snow Landsc Res 77:161-170

Senn J, Schönenberger W (2001) Zwanzig Jahre Versuchsaufforstung Stillberg: Überleben und Wachstum einer subalpinen
Aufforstung in Abhängigkeit vom Standort. Schweiz Z Forstwesen 152:226-246

SPLUS (2000) Professional Release 2, Copyright (C) 1988-1999 Math Soft Inc.

Sterba H, Blab A, Katzensteiner K (2002) Adapting an individual tree growth model for Norway spruce (Picea abies) in pure and mixed species stands. For Ecol Manage 159:101-110

Stewart JD, Landhäuser SM, Stadt KJ, Lieffers VJ (2001) Predicting natural regeneration of white spruce in boreal mixedwood understories. For Chron 77:1006-1013

Turner H (1988) Mikroklimate in der Versuchsfläche Stillberg. Schweiz Z Forstwesen 139:751-762

Wohlgemuth T, Kull P (2002) Disturbance of microsites and early tree regeneration after catastrophic windthrow Vivian 1990 in Swiss mountain forests. For Snow Landsc Res 77:17-47

Zeide B (1989) Accuracy of equations describing diameter growth. Can J For Res 19:1283-1286

Zeide B (1993) Analysis of growth equations. For Sci 39:594-516

Zhang S, Burkhart HE, Amateis RL (1996) Modeling individual tree growth for juvenile lobolly pine plantations. For Ecol Manage 89:157-172 